\title{
Erratum to: Editorial for MONET Special Issue on Networking in 5G Mobile Communications Systems: Key Technologies and Challenges
}

\author{
Xiaohu Ge $^{1}$ • Joel J. P. C. Rodrigues ${ }^{2,3} \cdot$ Bo Rong $^{4}$
}

Published online: 21 December 2015

(C) Springer Science+Business Media New York 2015

Erratum to: Mobile Netw Appl (2015) 20:701-703

DOI 10.1007/s11036-015-0606-3

The original version of this article unfortunately contained a mistake in the affiliation section. Dr. Joel J. P. C. Rodrigues should be affiliated with two organizations as corrected below.

The online version of the original article can be found at http://dx.doi.org/ 10.1007/s11036-015-0606-3.

\section{Xiaohu Ge}

xhge@mail.hust.edu.cn

1 School of Electronic Information and Communications, HUST, 1037 Luoyu Rd, Hongshan, Wuhan, Hubei, China

2 Instituto de Telecomunicações, University of Beira Interior, Covilhã, Portugal

3 University of Fortaleza (UNIFOR), Ceará, Brazil

4 Communications Research Centre Canada, Ottawa, ON, Canada 